\title{
Selectively grown photonic crystal structures for high efficiency InGaN emitting diodes using nanospherical-lens lithography
}

\author{
Tongbo Wei, ${ }^{1, a)}$ Kui Wu, ${ }^{1}$ Ding Lan, ${ }^{2}$ Qingfeng Yan, ${ }^{3}$ Yu Chen, ${ }^{1}$ Chengxiao Du, ${ }^{1}$ \\ Junxi Wang, ${ }^{1}$ Yiping Zeng, ${ }^{1}$ and Jinmin $\mathrm{Li}^{1}$ \\ ${ }^{1}$ State Key Laboratory of Solid-State Lighting, Institute of Semiconductors, Chinese Academy of Sciences, \\ Beijing 100083, China \\ ${ }^{2}$ National Microgravity Laboratory, Institute of Mechanics, Chinese Academy of Sciences, Beijing 100080, \\ China \\ ${ }^{3}$ Department of Chemistry, Tsinghua University, Beijing 100084, China
}

(Received 14 September 2012; accepted 30 October 2012; published online 21 November 2012)

\begin{abstract}
We report a low-cost and high-throughput process for the fabrication of two-dimensional $\mathrm{SiO}_{2}$ photonic crystal $(\mathrm{PhC})$ by nanospherical-lens photolithography method to improve the light extraction of GaN-based light-emitting diodes (LEDs). The PhC structures were realized by the selective area growth of $p$-GaN using $\mathrm{SiO}_{2}$ nanodisks, which were patterned utilizing a self-assembled nanosphere as an optical lens. Without prejudice to the electrical properties of LEDs, the light output power (at $350 \mathrm{~mA}$ ) of LEDs with the $\mathrm{SiO}_{2}$ and corresponding air-hole $\mathrm{PhC}$ was enhanced by $71.3 \%$ and $49.3 \%$, respectively, compared to that without PhC. The LEDs with selectively grown $\mathrm{PhC}$ structures were found to exhibit partial compression strain release and reduced emission divergence. The finite-difference time-domain simulation was also performed to further reveal the emission characteristics of PhC LEDs. (C) 2012 American Institute of Physics. [http://dx.doi.org/10.1063/1.4767334]
\end{abstract}

III-nitride wide bandgap light-emitting diodes (LEDs) have recently attracted considerable interest due to their various applications, such as traffic signals, back-side lighting in liquid crystal display, and illumination lighting by white light LEDs. However, a majority of applications are currently hindered by the low extraction efficiency and Lambertian-like radiation profile caused by the large difference of the refractive index between LED die and external medium. Various techniques used to increase light extraction, including surface texturing, ${ }^{1,2}$ patterned sapphire substrate (PSS), ${ }^{3}$ and photonic crystal $(\mathrm{PhC}),{ }^{4,5}$ have been proposed for GaN-based LEDs. Specifically, PhCs have drawn much attention since nanostructures formed by materials having a spatially periodic refractive index could efficiently couple light from the dielectric-guided modes into air, and then be utilized to inhibit the emission of the guided modes or to redirect trapped light into the radiated modes. At present, the $\mathrm{PhC}$ structures are usually fabricated by e-beam lithography, ${ }^{6}$ holographic lithography, ${ }^{7,8}$ and nanoimprint. ${ }^{9,10}$ However, the drawback of the e-beam and holographic lithography techniques is low throughput, and nanoimprint technique is required to produce the expensive hard mold for imprinting.

For the consideration of mass production and cost effect, nanosphere lithography (NSL) has been proposed as an efficient technique for the fabrication of PhC nanostructure. ${ }^{11,12}$ This technique is a simple and an economic process using a self-assembled monolayer of spheres, which acts as either an etching mask or lift-off layer. However, the size and spacing of the holes produced by NSL are coupled, and hence, these properties are hardly independently controlled. Additionally,

\footnotetext{
${ }^{\text {a) }}$ Author to whom correspondence should be addressed. Electronic mail: tbwei@semi.ac.cn. Tel: +86-10-82305304. Fax: +86-10-82305245.
}

NSL requires spheres to be formed directly on the substrate surface, and the remnants easily contaminate the surface. Here, we introduce an alternative method to fabricate $\mathrm{PhC}$, nanospherical-lens photolithography (NLP), using the single layer transparent polystyrene (PS) spheres as optical lenses ${ }^{13}$ to generate sub-wavelength holes on photoresist (PR) by focusing UV light. In this Letter, hexagonal-lattice $\mathrm{SiO}_{2} \mathrm{PhC}$ structures at the $p$-type $\mathrm{GaN}: \mathrm{Mg}$ surface are fabricated through NLP and selective area epitaxy (SAE) method, avoiding the use of plasma etching. The optical and electrical performances of the LEDs with different $\mathrm{PhC}$ are analyzed and discussed in detail. Finally, optical field distributions are simulated based on the finite-difference time domain (FDTD) method to verify the experimental results.

The blue InGaN/GaN LEDs were grown on a $c$-plane sapphire by metalorganic chemical vapor deposition (MOCVD). After growth of a $30 \mathrm{~nm}$ thick GaN nucleation layer at $550^{\circ} \mathrm{C}$, a $2 \mu \mathrm{m}$ thick undoped $\mathrm{GaN}$ layer and a $2 \mu \mathrm{m}$ thick $\mathrm{n}$-GaN layer were grown at $1030^{\circ} \mathrm{C}$. Then, eight periods of $\mathrm{In}_{0.2} \mathrm{Ga}_{0.8} \mathrm{~N} / \mathrm{GaN}$ multiple quantum wells (MQWs) were grown at $740^{\circ} \mathrm{C}$, followed by the growth of a $100 \mathrm{~nm}$ thick $p$-GaN layer at $950^{\circ} \mathrm{C}$. The $\mathrm{SiO}_{2} \mathrm{PhC}$ LEDs by NLP are fabricated according to the process flow illustrated in Fig. 1. First, a self-assembled monolayer of PS nanospheres was formed on the $p$-GaN surface with a closely packed mode as shown in our previous report, ${ }^{14}$ on which the $500 \mathrm{~nm}$ thick AR-P 3120 had been spun and baked on a hotplate at $90^{\circ} \mathrm{C}$ for $15 \mathrm{~min}$. Then, the wafer was UV-exposed for 2-5 s using a conventional photolithography instrument. After the elimination of PS by ultrasonication in deionized water, the wafer was developed in the diluted AR 300-26 developer and the size of air holes on PR may be tuned by controlling the developing time. Subsequently, $150 \mathrm{~nm}$ thick $\mathrm{SiO}_{2}$ layer was sputtered on patterned PR using an Oxford 
Spinning PS on PR + UVExposure
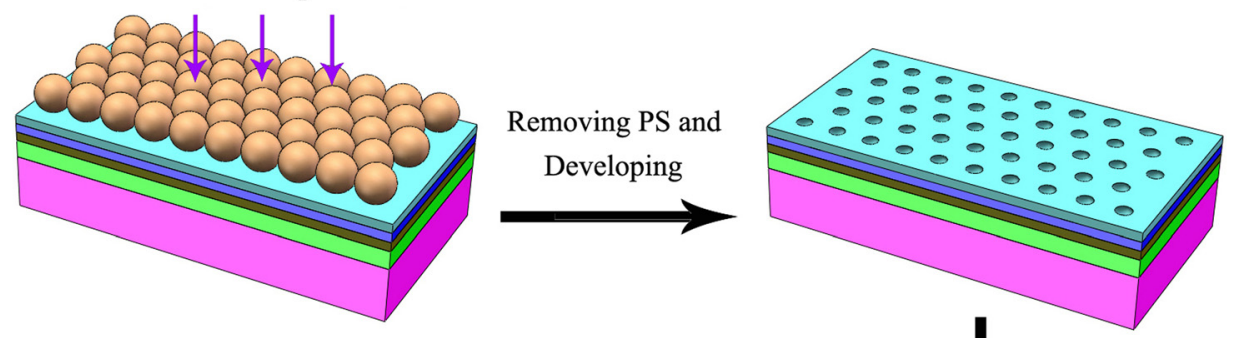

$\mathrm{SiO}_{2}$ Deposition

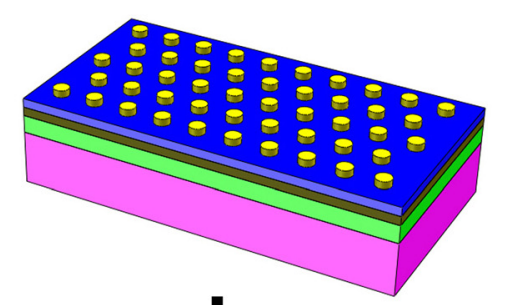

Selective regrowth

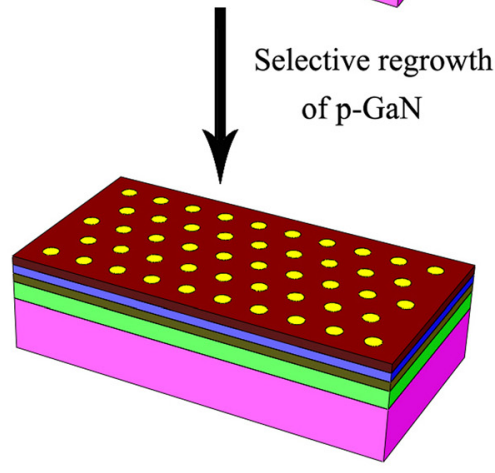

Removing $\mathrm{SiO}_{2}$ nanodisk arrays
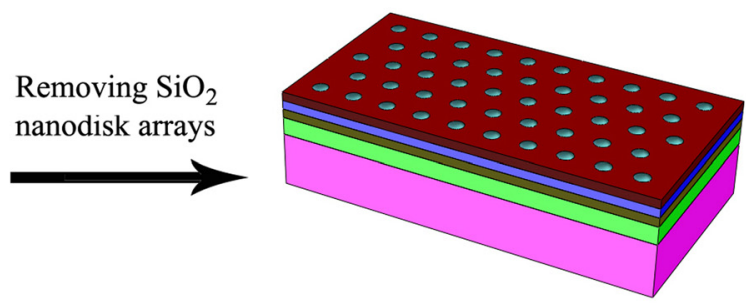

PR
n-GaN

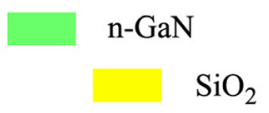

\section{InGaN MQWs}

Regrowth of $\mathrm{p}-\mathrm{GaN}$
FIG. 1. Schematic illustration of process for fabricating $\mathrm{SiO}_{2} \mathrm{PhC}$ LEDs and airhole PhC LEDs by NLP method.
Optofab3000 ion beam sputter at room temperature and a pressure of approximately $10^{-4}$ Torr. Lift-off process was then carried out by dissolving the PR in acetone for $30 \mathrm{~min}$, which produced the arrays of $\mathrm{SiO}_{2}$ nanodisk. Thus, the $p$-GaN filled the surrounding region of $\mathrm{SiO}_{2}$ nanodisk arrays after selective regrowth of $p$-GaN at $950^{\circ} \mathrm{C}$ for $7 \mathrm{~min}$, with a thickness of about $150 \mathrm{~nm}$. As a result, the periodic $\mathrm{PhC}$ structure of $\mathrm{SiO}_{2}$ and $p-\mathrm{GaN}$ with different refractive indices was formed. For comparison, air-hole $\mathrm{PhC}$ was also prepared by removing the $\mathrm{SiO}_{2}$ nanodisks using a $\mathrm{HF}$ solution. Finally, the PhC LEDs were fabricated with a conventional square mesa $\left(1 \times 1 \mathrm{~mm}^{2}\right)$ using indium tin oxide (ITO) with a thickness of $200 \mathrm{~nm}$ as a transparent current spreading layer (TCL) and $\mathrm{Cr} / \mathrm{Pt} / \mathrm{Au}$ as the $n$ - and $p$-electrodes by e-beam evaporation.

Tilted scanning electron microscopy (SEM) images of the hole arrays on PR by NLP and the resulting $\mathrm{SiO}_{2}$ nanodisk arrays are shown in Figs. 2(a) and 2(b). A large area of highly uniform round-shaped holes with a clear undercut structure can be generated, which completely penetrate through the $500 \mathrm{~nm}$ thick PR. After lift-off, the $150 \mathrm{~nm}$ thick $\mathrm{SiO}_{2}$ nanodisks with hexagonal-lattice are well produced, with a diameter of about $450 \mathrm{~nm}$ determined by the developing time and the periodicity of 900 and $700 \mathrm{~nm}$ tuned by different PS nanosphere diameters. After the selective regrowth, the space between $\mathrm{SiO}_{2}$ nanodisks is filled with flat $p-\mathrm{GaN}$ for the sample with a period of $900 \mathrm{~nm}$, as shown in Fig. 2(c). In contrast, bowl-shaped $p$-GaN with inclined facet is formed for that with a period of $700 \mathrm{~nm}$ due to the narrower vacant space in Fig. 2(e). The superfluous reactants accumulated in the narrow space lead to the fast growth and change the surface pattern of $p-\mathrm{GaN}$. Here, the height of regrown $p-\mathrm{GaN}$ is $150 \mathrm{~nm}$ and $220 \mathrm{~nm}$ for that with a $\mathrm{PhC}$ period of 900 and $700 \mathrm{~nm}$, respectively. Figures 2(d) and 2(f) show the corresponding SEM images of the air-hole patterned $p$-GaN layer after removing the $\mathrm{SiO}_{2}$ nanodisks, without suffering from the ICP etching damage.

The current-voltage $(I-V)$ and intensity-current $(L-I)$ characteristics of LEDs with and without $\mathrm{PhC}$ structure are shown in Fig. 3(a). The forward voltages at $350 \mathrm{~mA}$ dc current are $3.15,3.23,4.37,3.21$ and $3.51 \mathrm{~V}$ for the conventional LED, 900 and $700 \mathrm{~nm}$ period $\mathrm{SiO}_{2} \mathrm{PhC}$ LED, 900 and $700 \mathrm{~nm}$ period air-hole PhC LED, respectively. The operating voltages of $\mathrm{SiO}_{2}$ and air-hole PhC LEDs with a period of $700 \mathrm{~nm}$ are obviously higher compared to that of without $\mathrm{PhC}$, which is caused by a non-ohmic contact property between the bowl-shaped $p$-GaN and ITO layers. However, it is also noted the PhC LEDs with a period of $900 \mathrm{~nm}$ do not 

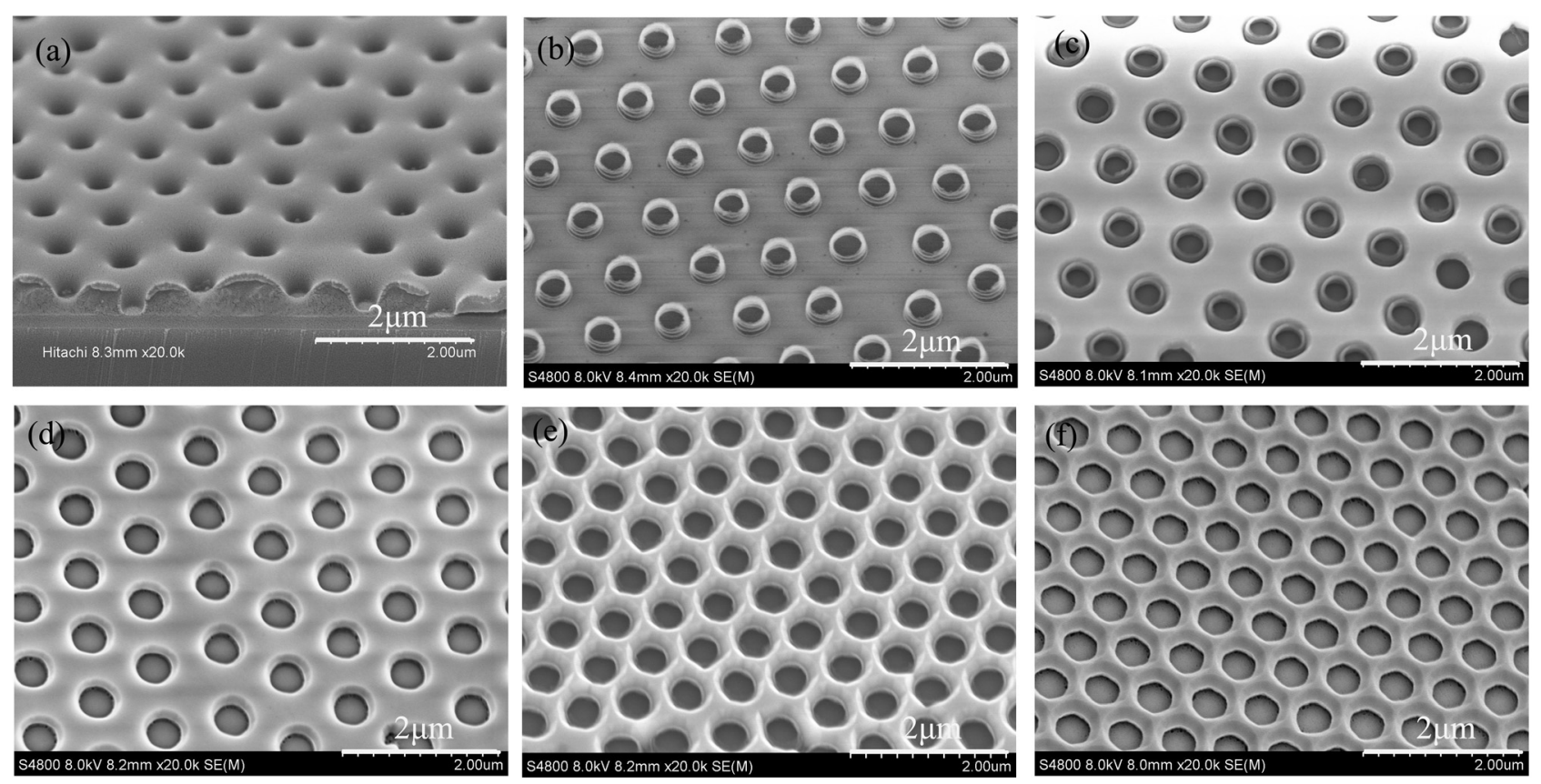

FIG. 2. Tilted SEM images of (a) $\mathrm{PR}$ nanoholes and (b) $150 \mathrm{~nm}$ thick $\mathrm{SiO}_{2}$ nanodisk arrays after lift-off. (c) $900 \mathrm{~nm}$ and (e) $700 \mathrm{~nm}$ period $\mathrm{SiO}_{2} \mathrm{PhC}$ structures with a diameter of $450 \mathrm{~nm}$ regrown by SAE on $p-\mathrm{GaN}$. (d) and (f) are the corresponding air-hole $\mathrm{PhC}$ of (c) and (e) after removing $\mathrm{SiO}_{2}$, respectively.

cause the degradation of electrical properties, attributed to high quality regrown $p-\mathrm{GaN}$ with flat surface. At $350 \mathrm{~mA}$ current, the light output power of $\mathrm{SiO}_{2}$ PhC LEDs with 900 and $700 \mathrm{~nm}$ period and air-hole PhC LEDs with 900 and $700 \mathrm{~nm}$ period are enhanced by $71.3 \%, 83.8 \%, 49.3 \%$, and $67.7 \%$, respectively, compared to that without $\mathrm{PhC}$ structure. The higher enhancement of $\mathrm{SiO}_{2} \mathrm{PhC}$ LEDs than those with air-hole $\mathrm{PhC}$ is caused due to the bigger incident angle by the PhC Bragg diffraction, which introduces the medium refractive index between $p-\mathrm{GaN}$ and air ambient. Additionally, besides PhC Bragg scattering, the contribution to the light enhancement are also related to the diffused scattering of light for PhC LED with a period of $700 \mathrm{~nm}$ due to the formation of the bowl-shaped $p-\mathrm{GaN}$ with the inclined facet. Furthermore, the corresponding wall-plug efficiencies (WPE) of $\mathrm{SiO}_{2} \mathrm{PhC}$ LEDs with 900 and $700 \mathrm{~nm}$ period and air-hole PhC LEDs with 900 and $700 \mathrm{~nm}$ period are enhanced by
$67.1 \%, 32.2 \%, 46.4 \%$, and $50.5 \%$, respectively, compared to that without $\mathrm{PhC}$ structure, which addresses a substantial improvement by the $\mathrm{PhC}$ structures at a current of $350 \mathrm{~mA}$. Overall, the $900 \mathrm{~nm} \mathrm{SiO} \mathrm{PhC}_{2}$ is the most suitable for the improvement of LED performance.

The peak wavelength of the EL spectra in the conventional LED, 900 and $700 \mathrm{~nm}$ period $\mathrm{SiO}_{2}$ PhC LEDs, 900 and $700 \mathrm{~nm}$ period air-hole $\mathrm{PhC}$ LEDs are measured as $447.6,442.4,445.9,441.3$, and $444.1 \mathrm{~nm}$ at a $350 \mathrm{~mA}$ operating current in Fig. 3(b). The EL spectrums illustrate 3.2 and $1.7 \mathrm{~nm}$ blue-shift phenomena in 900 and $700 \mathrm{~nm}$ period $\mathrm{SiO}_{2}$ PhC LEDs, respectively, compared with the conventional LED. This blue-shift phenomenon in the EL spectra is caused by a partial compression strain release in the InGaN active layer through the SAE regrowth of $p$-GaN. Here, the compression strain of $700 \mathrm{~nm} \mathrm{SiO}_{2} \mathrm{PhC}$ LED is slightly larger than that with $900 \mathrm{~nm}$ period $\mathrm{SiO}_{2} \mathrm{PhC}$ due to high
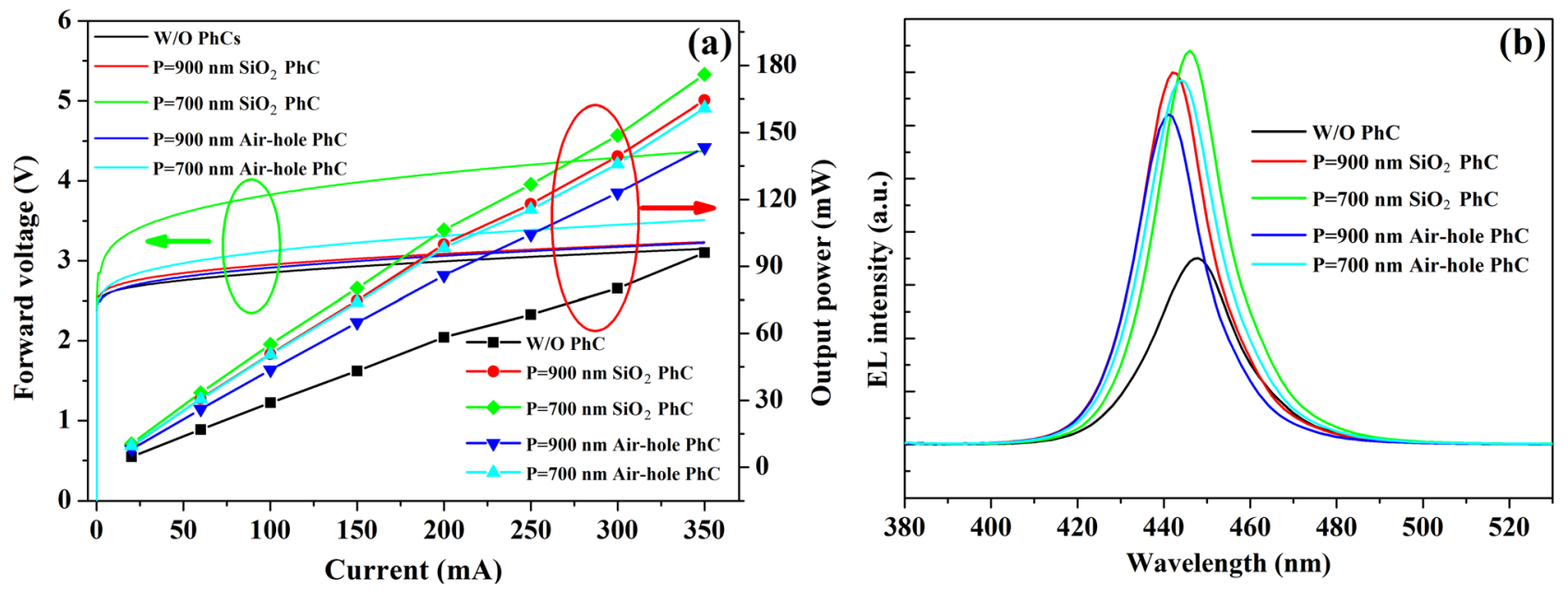

FIG. 3. (a) Forward voltages and light output powers of LEDs with and without PhC structures as the functions of injecting current. (b) Peak wavelengths of the EL emission spectra of the LEDs at a driving current of $350 \mathrm{~mA}$. 
growth rate of $p$-GaN in the narrow space during the SAE process. After removing the $\mathrm{SiO}_{2}$ nanodisks, the compression strain in the InGaN MQWs of air-hole PhC LEDs is further released compared with that with $\mathrm{SiO}_{2} \mathrm{PhC}$.

Figure 4(a) shows the angular emission profiles of the LEDs with and without $\mathrm{PhC}$ operated at $200 \mathrm{~mA}$. Here, the chips were Au-wire bonded and loaded on an aluminium leaded chip carrier without epoxy encapsulation. As determined from the radiation patterns, the full-width-at-half maximum (FWHM) of emission divergence for 900 and $700 \mathrm{~nm}$ period $\mathrm{SiO}_{2} \mathrm{PhC}$ LED, 900 and $700 \mathrm{~nm}$ period air-hole $\mathrm{PhC}$ LED are $137.8^{\circ}, 132.5^{\circ}, 143.2^{\circ}$, and $138.6^{\circ}$, respectively, compared to that of $151.3^{\circ}$ for LED without $\mathrm{PhC}$. The larger divergent angle observed for LED without $\mathrm{PhC}$ implies that the light confined in the LED chip is extracted from edge of the chip or of the sapphire substrate after multiple scattering or reflection events. ${ }^{15}$ For PhC LEDs, the light is effectively redirected to the top escape-cone of the LED through $\mathrm{SiO}_{2}$ and air-hole structures, resulting in the smaller divergent angle. Particularly, the LED with $700 \mathrm{~nm}$ period $\mathrm{SiO}_{2} \mathrm{PhC}$ is found to produce the most significant focusing effect with respect to that without $\mathrm{PhC}$, demonstrating a divergence reduction of $18.8^{\circ}$ (FWHM). This is attributed the combined effect of narrower beam profile from $\mathrm{SiO}_{2} \mathrm{PhC}$ structure and concave pattern of the bowl-shaped $p-\mathrm{GaN}$ produced by SAE on the surface. Unlike the random scattering of surface roughness, the bowl-shaped $p$-GaN helps to confine the light to radiate in vertical direction, effectively reducing the energy confined in the LED slab.

To further understand the effect of $\mathrm{PhC}$ patterns on LEDs, a two-dimensional (2D) FDTD simulation is used. Here, considering the plane isotropy of hexagonal $\mathrm{PhC}$ structures, the simulation model is simplified from $3 \mathrm{D}$ to $2 \mathrm{D}$ to reduce the calculation time. In the simulation, the representative $\mathrm{SiO}_{2} \mathrm{PhC}$ are chosen to carry out and the absorption effect is ignored. The simulated LED structure consists of $250-320 \mathrm{~nm}$ thick $p-\mathrm{GaN} / 150 \mathrm{~nm}$ thick MQWs $/ 4 \mu \mathrm{m}$ thick $n$-GaN/10 $\mu$ m sapphire substrate. The shape and size of the $\mathrm{SiO}_{2} \mathrm{PhC}$ solid model for FDTD simulation are determined and are exactly the same as those in the SEM images in Fig. 2. We use the perfectly matched layer (PML) boundary condition for the simulation and a point dipole polarized along the $\mathrm{x}, \mathrm{y}$, and $\mathrm{z}$ directions is used as a radiation source. Figures 4(b)-4(d) compare the propagation of electromagnetic waves passing through $\mathrm{SiO}_{2} \mathrm{PhC}$ structures and hybrid surface. Obviously, the incorporation of $\mathrm{SiO}_{2} \mathrm{PhC}$ is seen to suppress lateral guiding modes and diffract the optical energy to the surface normal. Generally, the $\mathrm{PhC}$ interacts more strongly for a smaller lattice constant with the loworder guided modes. ${ }^{16}$ In view of dimension of $\mathrm{SiO}_{2}$ equal to wavelength, wave-like features such as interference and diffraction dominate the interface between $p-\mathrm{GaN}$ and air, thereby resulting in improved light extraction. It is also noted that the $700 \mathrm{~nm}$ period $\mathrm{PhC}$ exhibits the most distinct converging effect and the field density under the $\mathrm{PhC}$ is weaker compared to the case of $900 \mathrm{~nm}$ period $\mathrm{PhC}$ and without $\mathrm{PhC}$. It is also evident that the bowl-shaped $p$-GaN can favor of coupling out guided energy into normal direction. The simulation results are consistent with the observation of far-field emission patterns of the LEDs in Fig. 4(a). The inset of Figs. 4(b)-4(d) presents the corresponding optical microphotographs of the PhC LEDs operated at low injection current $2 \mathrm{~mA}$. The significantly high intense luminescence is observed at the $\mathrm{PhC}$ structures, which facilitate the multiple chances for photons to escape from the LEDs as guided light deflectors. The light intensity around the $\mathrm{PhC}$ of $700 \mathrm{~nm}$ period is brighter compared to the intensity around the $\mathrm{PhC}$ of $900 \mathrm{~nm}$ period, validating the bowl-shaped structure existed between the $\mathrm{SiO}_{2}$ nanodisks enhances the extraction of photons.

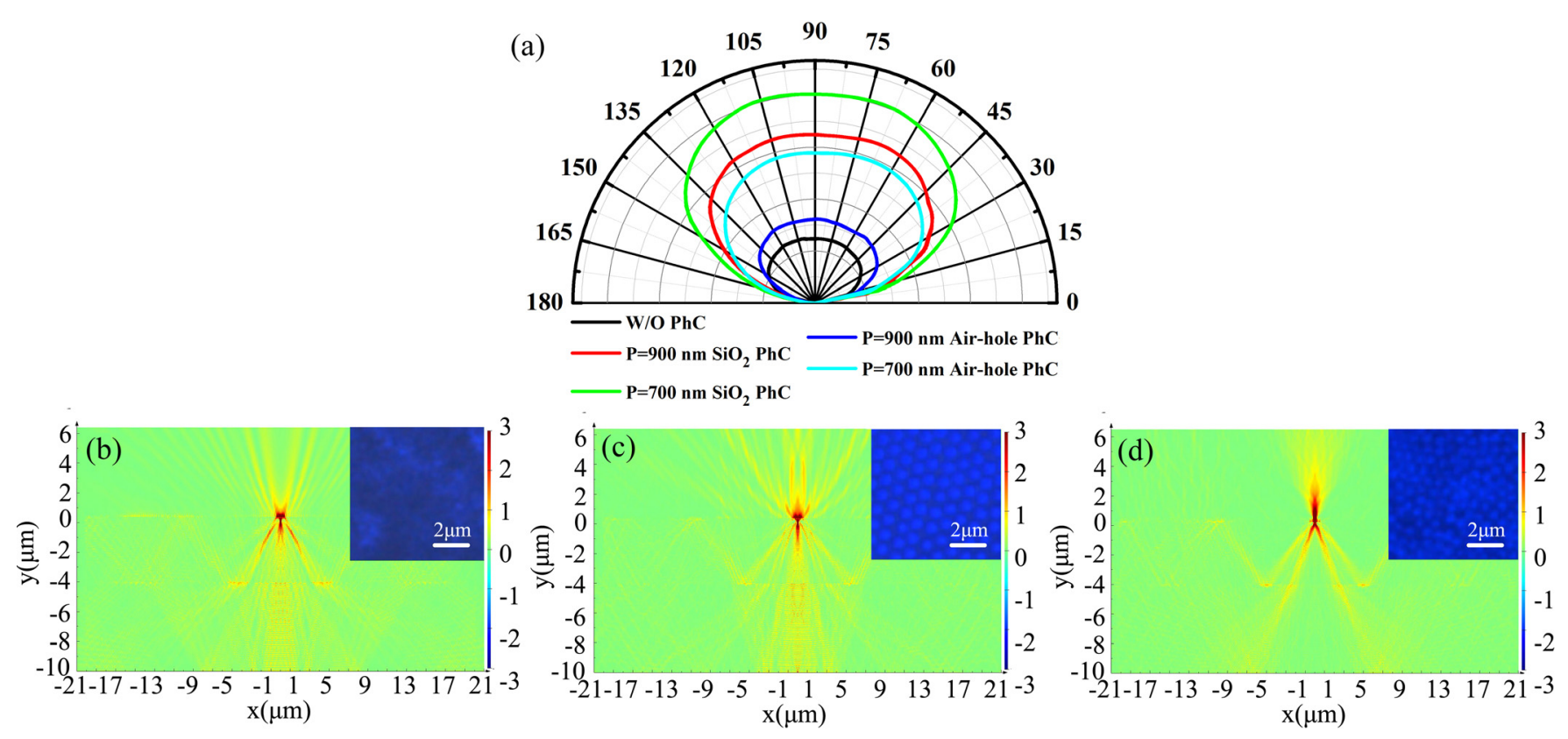

FIG. 4. (a) Far-field emission patterns of the LEDs with and without PhC structures. FDTD simulation of light propagation in (b) LED without PhC, LED with (c) $900 \mathrm{~nm}$ and (d) $700 \mathrm{~nm}$ period $\mathrm{SiO}_{2} \mathrm{PhC}$. The inset shows the corresponding optical microphotographs of the above LEDs operated at low injection current $2 \mathrm{~mA}$. 
In summary, high-quality $2 \mathrm{D} \mathrm{SiO}_{2} \mathrm{PhC}$ followed $\mathrm{SAE}$ regrowth were fabricated on the $p-\mathrm{GaN}$ surface of $\mathrm{GaN}$ based LED by NLP process utilizing the focusing behavior of PS nanospheres. Significant improvements on light extraction of the $\mathrm{SiO}_{2}$ and corresponding air-hole $\mathrm{PhC}$ LEDs had been observed of up to $71.3 \%$ and $49.3 \%$ over the conventional LED, respectively, leaving the $p$-GaN damage-free. The blueshift phenomenon in EL emission spectrums was observed in the PhC LEDs due to the partial release compressive strain during SAE growth. The $\mathrm{SiO}_{2} \mathrm{PhC}$ LED with the bowl-shaped $p$-GaN exhibited the most significant focusing effect and highest light output power, which was consistent with FDTD simulation results.

This work was supported by the National Natural Sciences Foundation of China under Grant Nos. 61274040 and 61274008, by the National Basic Research Program of China under Grant No. 2011CB301902, and by the National High Technology Program of China under Grant No. 2011AA03A103.

${ }^{1}$ Y. K. Ee, R. A. Arif, N. Tansu, P. Kumnorkaew, and J. F. Gilchrist, Appl. Phys. Lett. 91, 221107 (2007).

${ }^{2}$ T. B. Wei, Q. F. Kong, J. X. Wang, J. Li, Y. P. Zeng, G. H. Wang, J. M. Li, Y. X. Liao, and F. T. Yi, Opt. Express 19, 1065 (2011).

${ }^{3}$ C. H. Chan, C. H. Hou, S. Z. Tseng, T. J. Chen, H. T. Chien, F. L. Hsiao, C. C. Lee, Y. L. Tsai, and C. C. Chen, Appl. Phys. Lett. 95, 011110 (2009).
${ }^{4}$ T. N. Oder, K. H. Kim, J. Y. Lin, and H. X. Jiang, Appl. Phys. Lett. 84, 466 (2004).

${ }^{5}$ C.-H. Hou, S.-Z. Tseng, C.-H. Chan, T.-J. Chen, H.-T. Chien, F.-L. Hsiao, H.-K. Chiu, C.-C. Lee, Y.-L. Tsai, and C.-C. Chen, Appl. Phys. Lett. 95, 133105 (2009).

${ }^{6}$ C. F. Lai, H. C. Kuo, C. H. Chao, H. T. Hsueh, J. F. T. Wang, W. Y. Yeh, and J. Y. Chi, Appl. Phys. Lett. 91, 123117 (2007).

${ }^{7}$ D.-H. Kim, C.-O. Cho, Y.-G. Roh, H. Jeon, Y. S. Park, J. Cho, J. S. Im, C. Sone, Y. Park, W. J. Choi, and Q.-H. Park, Appl. Phys. Lett. 87, 203508 (2005).

${ }^{8}$ M.-K. Kwon, J.-Y. Kim, I.-K. Park, K. S. Kim, G.-Y. Jung, S.-J. Park, J. W. Kim, and Y. C. Kim, Appl. Phys. Lett. 92, 251110 (2008).

${ }^{9}$ S. H. Kim, K.-D. Lee, J.-Y. Kim, M.-K. Kwon, and S.-J. Park, Nanotechnology 18, 055306 (2007)

${ }^{10}$ H. W. Huang, C. H. Lin, K. Y. Lee, C. C. Yu, J. K. Huang, B. D. Lee, H. C. Kuo, K. M. Leung, and S. C. Wang, Semicond. Sci. Technol. 24, 085008 (2009).

${ }^{11}$ W. Y. Fu, K. K.-Y. Wong, and H. W. Choi, Appl. Phys. Lett. 95, 133125 (2009).

${ }^{12}$ Y.-C. Chang, S.-M. Wang, H.-C. Chung, C.-B. Tseng, and S.-H. Chang, ACS Nano 6, 3390 (2012).

${ }^{13}$ W. Wu, A. Katsnelson, O. G. Memis, and H. Mohseni, Nanotechnology 18, 485302 (2007).

${ }^{14}$ T. B. Wei, K. Wu, Y. Chen, J. Yu, Q. Yan, Y. Y. Zhang, R. Duan, J. Wang, Y. Zeng, and J. M. Li, IEEE Electron Device Lett. 33, 857 (2012).

${ }^{15}$ Y. J. Lee, J. M. Hwang, T. C. Hsu, M. H. Hsieh, M. J. Jou, B. J. Lee, T. C. Lu, H. C. Kuo, and S. C. Wang, IEEE Photon. Technol. Lett. 18, 1152 (2006).

${ }^{16}$ J. J. Wierer, M. R. Krames, J. E. Epler, N. F. Gardner, M. G. Craford, J. R. Wendt, J. A. Simmons, and M. M. Sigalas, Appl. Phys. Lett. 84, 3885 (2004). 